\title{
The Impact of the COVID-19 Epidemic Risk on the Financial System and Countermeasures
}

\author{
Nieying $\mathrm{Xu}^{1}$ Chengyi $\mathrm{Pu}^{2}$, * \\ ${ }^{1}$ Nieying Xu, School of Insurance, Central University of Finance and Economics, Email:xunieyingyoung@163.com \\ 2 * Chengyi Pu. Corresponding author. Central University of Finance and Economics, School of Insurance .Email: \\ pucy@cufe.edu.cn
}

\begin{abstract}
The COVID-19 pneumonia epidemic broke out and spread across the world, causing residents to stay at home, causing service industries such as commerce, catering, culture and entertainment, and holiday tourism to cease business almost instantly, interrupting most of the transportation and business suspension, real economic activities almost halting, causing financial market transactions behaviors have shrunk drastically, and promoting coordination between finance and the real economy is the current priority. Predecessors have studied the financial systemic impact of sudden public health event catastrophe risk on financial system. This paper selects a model suitable for my country's systemic financial risk evaluation, the comprehensive index method model, to study the macro-effects and micro-mechanisms of sudden public health event catastrophe risks on financial systemic shocks, and discovers the impact of the COVID-19 pneumonia epidemic on my country's financial The market has mainly produced the following impacts: (1) Uncertainties in the financial market have increased; (2) The government-led risk supervision and management system, through the injection of liquidity into the market, targeted tax reduction and exemption, and social insurance premium reduction and exemption systems, To a certain extent, the rationality of financial market circulation is realized. Combining the mechanism of the epidemic's impact on systemic financial risks and the response of China's financial market, some suggestions are made for China's future response to catastrophe risks of sudden public health events:
\end{abstract}

Keywords: Systemic Financial Risks, New Type of Coronary Pneumonia, Emergent Public Health Events

\section{新冠肺炎疫情风险对金融系统的冲击与应对}

\author{
徐聂英 1 蒲成毅 2 ,*
}

\author{
1 徐聂英, 保险学院中央财经大学 保险学院, 电子邮箱: xunieyingyoung@163.com \\ $2 *$ 蒲成毅(通讯作者), 中央财经大学, 保险学院，电子邮箱： pucy@cufe.edu.cn
}

\begin{abstract}
摘要
新冠肺炎疫情爆发并蔓延全球，导致居民居家隔离，引起商贸餐饮、文化娱乐、度假旅游等服务业几乎 瞬间停业，中断大部分交通和企业停工停产，实体经济活动几乎停止，引起金融市场交易行为剧烈萎缩， 促进金融与实体经济相协调是当前重点任务。前人研究突发性公共卫生事件类巨灾风险对金融系统性冲 击的文献较少。本文选择了适合我国系统性金融风险评价的模型，综合指数法模型，研究突发性公共卫 生事件类巨灾风险对金融系统性冲击的宏观效应及其微观机理，发现了新冠肺炎疫情对我国金融市场主 要产生了下列影响：（1）金融市场不确定因素增加;（2）以政府为主导的风险监督管理制度，通过向市 场注入流动性, 针对性的税收减免以及社会保费减免制度, 在一定程度上实现了金融市场流通的合理性。 结合疫情对系统性金融风险的影响机制以及中国金融市场的应对方式，对我国以后应对突发性公共卫生 事件类巨灾风险提出几点建议.
\end{abstract}

关键字: 系统性金融风险，新型冠状肺炎，突发性公共卫生事件 


\section{1. 引言}

2019 年 12 月份, 新型冠状肺炎疫情开始从中 国武汉爆发并蔓延至全球。截止 2020 年四月底, 全国确诊累计超过八万两千病例。全球疫情局势仍 然不容乐观。虽然在中国政府强有力的政策指导下， 中国国内疫情基本稳定, 但境外局势不论从病死率 还是累计确诊人数上看, 新冠疫情都已经严重威胁 人类生命安全。截止 2020 年 4 月底, 全球新冠肺 炎确诊人数累计超过三百万例, 截止 8 月 15 号确 诊超两千万例。随着疫情的发展, 国际经济情况不 容乐观, 甚至引发学者关于此次疫情能否引发经济 危机的论断。全球股市剧烈波动, 在 2009 年之后 出现了罕见的道斯琼指数多次触发熔断, 原油价格 暴跌甚至出现负结算价格, 市场投资者恐慌情绪扩 散增加整个金融系统风险, 超过中小型金融机构承 受范围, 带来巨大考验。我国金融系统相较与西方 金融市场还不成熟，系统性金融风险波动性较大， 投资者中个人投资者比例居高, 容易导致市场恐慌 情绪扩散和非理性投资行为, 急需改善风险监督和 防范措施。在此情况下, 研究新冠疫情对我国以股 票市场为代表的金融市场有十分重要的意义, 主要 体现在: 首先, 揭示类似公共卫生事件等外部风险 冲击因素对系统性金融风险的影响, 为探究深入的 影响机制提供理论基础; 其次研究外部冲击带来的 风险影响为投资者做出理智的投资行为提供参考, 为降低系统性金融风险做出贡献; 最后, 研究此类 风险的影响机制将为我国日后如何制定监督和防 范系统性金融风险的市场政策提供参考。

本文将在前人研究的基础上, 选择适合我国系 统性金融风险的评价模型。以新冠肺炎在中国开始 爆发并蔓延的时间作为节点, 时间段确定为节点前 后各五个月共十个月, 对比分析新冠肺炎在我国股 票市场中的影响程度。

\section{2. 文献综述}

\section{1 系统性金融风险概述}

系统性金融风险其含义有微观和宏观两方面, 微观层面的系统性金融风险指证券市场上不能通 过分散投资加以消除的风险 ${ }^{[1]}$ 。但是在当今国际环 境下备受关注的是宏观意义上的金融系统性风险, 由于其复杂的性质, 还没有学者给出权威的定义, 这也说明这个领域的研究非常有限, 需要进一步探 索和研究。Minsky (1995) 、Bernanke (2009)等学 者研究认为系统性金融风险是能够对金融系统的 功能造成冲击, 对市场或者宏观经济带来负面影响。 [2]国内学者也给出了相应定义, 张泉泉(2014)认为 系统性金融风险可以由宏观或微观层面的金融风
险系统性金融风险引起，王国刚(2017)认为是高杜 杆和虚拟经济基础上的金融交易引起，两位学者都 认为其对金融市场和经济都有负面冲击。[3]通过文 献的梳理, 我们发现系统性金融风险的成因主要有 内部因素和外部因素两种。内部因素指系统的自身 属性, 主要包括金融脆弱性、投资者非理性行为因 素, 外生因素主要指金融系统的外部冲击, 如宏观 货币政策、突发性公共卫生事件等。就政府政策干 预而言, 短期内能够解决经济的波动和发展问题, 但是长远看来影响了经济运行的自身规律, 引发经 济自我调节失调。例如美国学者泰勒研究发现美国 联邦政府的政策干预引发了 2007 年的次债危机以 及延长了其时间长度。由于近年来, 我国投资市场 上个体投资者数量显著上升, 但是投资者本身的心 理和知识范围属性导致系统性风险增加, 在突发性 公共卫生事件发生时, 投资者恐慌情绪攀升且不断 扩散，对系统性金融风险也有重要影响。

\section{2 突发性公共卫生事件历史回顾与文献梳理}

人类历史上历经多次传染病的大爆发事件, 如 中世界欧亚大陆鼠疫、19 世纪霍乱病毒肆虐、1918 年大量流感、2003 年 SARS 等。国际社会为加强 对此类公共卫生事件的全球防控，2007 年《国际 公共卫生条例》经修改后生效, 规定在一定条件时 世界卫生组织有权认定疫情构成国际关注的突发 公共卫生事件 (PHEIC)。这六次 PHEIC 分别为: 2009 年甲型 H1N1 流感从墨西哥开始扩散至全球 200 多个国家; 2014 年野生型脊髓灰质炎在叙利亚 等国家爆发, 患者多为儿童, 直接消耗社会成本造 成经济冲击； 2014 年西非埃博拉席卷西非，高致 死率造成经济增速放缓但对全球的经济影响有限; 2016 年塞卡病毒在巴西大规模爆发，波及全球至 少 69 个国家，对巴西 GDP、旅游业、卫生保健系 统造成打击；2018 年埃博拉病毒在刚果等国家曼 延，打击当地脆弱经济；2019 年新型冠状病毒在 中国开始，日本、韩国、意大利等全球多个国家受 到波及，全球股市、黄金、原油等资产价格剧烈波 动; 疫情严重地区经济负面冲击; 全球价值链重构。 历史上被认定的历次疫情均有爆发周期短, 波及范 围广、危害程度深的特征, 因此对其采取危险防范 是极其必要的。

新冠疫情对经济的冲击程度是远远大于前五 次 PHEIC，中国金融市场经过快速发展到 2019 年 发展速度已经放缓, 此时的中国各部门杜杆率已较 高, 且全球市场经济处于下滑阶段, 日本与欧洲经 济增长迟缓。疫情影响着全球市场经济发展, 冲击 着国际金融稳定性。

重大突发事件对资本市场的有着重要影响。重 大突发事件主要分为自然灾害, 社会安全事件, 事 故灾难以及公共卫生事件。从世界各国的历史来看, 
以 911 事件为代表的社会安全事件和以各大传染 病为代表的公共卫生事件, 都引发了事故发生国的 股市动荡。国外学者 Worthington 和 Valadkhani 以 澳洲火灾、龙卷风和地震为研究对象, 发现此类自 然灾害对资本市场产生或正面或负面的影响。国内 叶志强、孔东民, 周燕飞和武帅锋等学者的相关研 究发现自然灾害对灾害当地资本板块产生显著的 负向影响，一定程度上影响了当地的长期投资，对 相关产业的影响也更为显著。现有研究表明, 对重 大突发性事件带来的金融风险的应对主要从宏观 和微观两个层面展开。宏观层面政府实施的财政政 策和货币政策对应对金融风险奠定了基础, 通过减 税降息、支持中小企业融资等途径抵御金融冲击。 微观层面应对措施主体主要有企业和个人投资者。 企业通过内部行为改善会计稳定性和公司治理方 式, 投资者对社会经济发展和资本市场高质量增长 持有信心, 对应对突发事件的金融冲击都至关重要。

\section{3. 系统性金融风险度量指标}

\section{1 假设前提}

(1) 本文研究中会将研究的金融系统界定为 以股票市场为主要市场的金融风险, 以股票市场有 足够强的代表性并且能充分体现新冠疫情带来的 金融冲击为前提。

（2）本文中所整理六个指标及其在研究时间 范围内的数据能够反应股票市场的风险和风险变 化程度。

（3）假设该比对实证研究中, 本文得出的六 个指标足够反映的新冠疫情对金融系统风险的影 响, 也即排除金融系统中其他复杂多变的影响因素。

\section{2 研究目的、对象、范围}

本文研究目的是探寻新冠疫情带给金融系统 的冲击、使金融系统风险发生了何种程度的变化, 进一步探究微观变化机理, 从而为我国金融系统未 来如何防范此类突发性公共卫生事件提供理论参 考。本文研究对象为系统性金融风险。根据全球金 融稳定理事会FSB 定义的系统性金融风险——“因 为全部或部分金融体系遭到损害而引起的金融服 务崩溃所带来的风险, 会对实体经济产生严重的负 面影响。” 由于数据的可获得性和模型的简化, 本 文将股票市场上发生的系统性金融风险作为主要 研究范围。该风险表明了产生股票价格猛烈衰退、 股市崩盘的可能性。选取股票市场这一子金融市场 主要有以下方面原因: 首先我国股票市场作为重要
的金融子市场直接影响实体经济的稳定发展。健康 稳定的股票市场能为实体经济提供资金从而提高 资源配置效率促进生产, 并且股票市场作为实体经 济的 “晴雨表”，从其发展水平与波动幅度能够预 测实体经济的发展状况。其次，和其他金融子市场 相比, 我国股票市场资金流通量大, 投资者数量多, 上市公司个数多, 更具有代表性和研究价值。随着 金融国际化发展, 股票市场的稳定性对国际金融市 场的稳定性的都深远影响, 对其风险研究有重要意 义。再次，我国股票市场的个人投资者比例高，投 资者非理性行为明显, 对反映研究投资者对系统性 金融风险的影响更有利。并且我国股票金融市场表 现出较强的波动性, 相对于其他金融市场而言更容 易产生系统性金融风险。最后，我国股票市场与实 体经济和其他金融子市场如货币市场、房地产市场、 债券市场的联系越来越紧密, 其复杂的联系使金融 风险很容易传染到其他子市场实质是实体经济, 所 以对股票市场的风险监督与防范对避免整个金融 系统危机爆发具有重要意义。

\section{3 逻辑思路}

首先, 本文研究中会将研究的金融系统界定为 股票市场上的金融风险，以股票市场有足够强的代 表性并且能充分体现新冠疫情带来的金融冲击为 前提。其次，本文选取了上市公司数量、总市值、 平均市盈率、换手率、上证综指波动率以及深证成 指波动率等六个指标。最后在对指标数据进行描述 性统计和多目标客观赋权法适用前提条件验证基 础上, 采取多目标客观赋权法对每个指标赋予相应 的权重, 根据评价金融系统风险的综合指数模型得 出每个月内的风险得分。最后结合实际对系统性金 融风险的发展变化做出实证分析, 揭示新冠肺炎疫 情对我国以股票市场为代表金融市场主要产生的 影响, 并对我国以后应对突发性公共卫生事件类巨 灾风险提出几点建议。

\section{4 指标选取}

考虑到研究市场范围定义为“股票市场的系统 性金融风险” 以及股市现状和数据的合理性、有效 性和可得性, 在原始数据基础的处理上得出最终确 定的指标，本文最后以股票市场的上市公司数量、 总市值、平均市盈率、平均市盈率、换手率、上证 综指波动率以及深证成指波动率 6 个指标构建我 国系统性金融风险度量指标体系。[4]

表 1 系统性金融风险指标体系

\begin{tabular}{cccc}
\hline 指标 & 编号 & 经济含义 & 与风险综合得分关系 \\
上市公司数量 & $\mathrm{X}_{1}$ & 体现了市场的活跃度以及风险受度 & 反向变化 \\
总市值 & $\mathrm{X}_{2}$ & 体现我国上市整体抵御风险的能力 & 反向变化 \\
\hline
\end{tabular}




\begin{tabular}{ccll}
\hline 平均市盈率 & $\mathrm{X}_{3}$ & 反映了上市公司的估值水平, 与基准值偏离越大, 风险越高 & 双向变化 \\
换手率 & $\mathrm{X}_{4}$ & 反映市场活跃度 & 双向变化 \\
上证综指波动率 & $\mathrm{X}_{5}$ & 波动率越高, 表示 $\mathrm{A}$ 股市场风险越大 & 正向变化 \\
深证成指波动率 & $\mathrm{X}_{6}$ & 波动率越高, 表示 $\mathrm{A}$ 股市场风险越大 & 正向变化 \\
\hline
\end{tabular}

\section{5 数据来源和描述性统计}

本文数据的时间长度分为两阶段, 新冠 疫情爆发于 2019 年 12 月, 采用 2019 年 7 月至 2019 年 11 月为第一阶段数据, 共 5 个
月; 采用 2019 年 12 月至 2020 年 4 月为第 二阶段数据, 共 5 个月。数据来源 Wind, 上海证券交易所，深圳证券交易所，锐思数 据库。各指标描述性统计如表 2 所示。

表 2. 描述性统计

\begin{tabular}{|c|c|c|c|}
\hline 时间 & 上市公司数量 & 总市值 & \\
\hline 2019 年 7 月 & 3682 & 53386187236869 & \\
\hline 2019 年 8 月 & 3697 & 52183394629388 & \\
\hline 2019 年 9 月 & 3708 & 55270460927980 & \\
\hline 2019 年 10 月 & 3723 & 54889452431128 & \\
\hline 2019 年 11 月 & 3792 & 54661125232872 & \\
\hline 2019 年 12 月 & 3777 & 56335288987110 & \\
\hline 2020 年 1 月 & 3792 & 59493871370892 & 25. \\
\hline 2020 年 2 月 & 3813 & 58595786666928 & \\
\hline 2020 年 3 月 & 3826 & 57528728604417 & \\
\hline 2020 年 4 月 & 3850 & 56703863956754 & 29.22 \\
\hline 最大值 & 3850 & $5.94939 \mathrm{E}+13$ & \\
\hline 最小值 & 3682 & $5.21834 \mathrm{E}+13$ & 23.2 \\
\hline 平均值 & 3766 & $5.59048 \mathrm{E}+13$ & 24.9 \\
\hline 标准差 & 59.03671174 & $2.27928 \mathrm{E}+12$ & 1.60 \\
\hline \multicolumn{4}{|c|}{$\begin{array}{l}\text { 其中上证综指波动率和深证成指波动 } \\
\text { 所每日收盘时指数原始数据的基础上, 依据 } \\
\text { 力史波动率的计算公式求得, 对上证综指和 } \\
\text { 罙证成指 } 10 \text { 个月内的走势图以及历史波动 } \\
\text { 率计算过程分别如图 2, 图 } 3 \text { 及下式所示。 } \\
\end{array}$} \\
\hline \\
\hline \multicolumn{4}{|c|}{$\begin{array}{l}8000 \\
6000\end{array}$} \\
\hline \multicolumn{4}{|c|}{4000} \\
\hline 2000 & & & \\
\hline
\end{tabular}

图 1 上证指数十个月内走势图

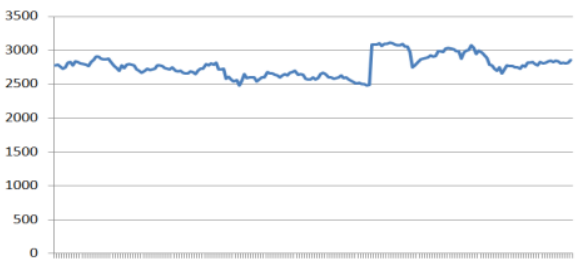

图 2 深证指数十个月内走势图

\section{6 综合指数的合成}

对所选的六个指标进行多目标客观赋权法 赋权。设有 $\mathrm{n}$ 个决策方案的集合

$\mathrm{A}=\left\{A_{1}, A_{2}, \ldots A_{n}\right\}$

其中 $A_{j}=\left(a_{1 j}, a_{2 j}, \ldots, a_{m j}\right)^{T}, j=1,2, \ldots n$ 是第 $\mathrm{j}$ 个方案, 关于 $\mathrm{m}$ 项评价因素的指标值 向量。得到 $\mathrm{n}$ 个方案关于 $\mathrm{m}$ 项评价因素的
指标矩阵

$$
\mathrm{A}=\left\{\begin{array}{llll}
a_{11} & a_{12} & \ldots & a_{1 n} \\
a_{21} & a_{22} & \ldots & a_{2 n} \\
a_{m 1} & a_{m 2} & \ldots & a_{m n}
\end{array}\right\}
$$

其中, aij 表示第 $\mathrm{j}$ 个方案关于第 $\mathrm{i}$ 项评价因 素的指标值。评价指标通常分为成本型、效 益型和适度性指标。成本型指标就是数值越 小越好的指标: 效益型指标是指数值越大越 
好的指标; 适度性指标是指数值越接近某个 常数越好的指标。具体步骤如下:

(1)建立各方案指标值得理想最优方案

$$
\begin{gathered}
U^{*}=\left(U_{1}^{*}, U_{2}^{*}, \ldots, U_{n}^{*}\right), \\
U *=\left(U_{1} *, U_{2} *, \ldots, U_{m} *\right)
\end{gathered}
$$

其中

$U_{i}^{*}=\left\{\begin{array}{c}\max \left\{a_{i j}\right\}(i \ll j \ll n) \\ \min \left\{a_{i j}\right\}\{i \ll j \ll n\} \\ a_{i} \pm \min \left|a_{i j}-a_{i}\right|(1 \ll j \ll n)\end{array}\right.$

$$
\left.\begin{array}{l}
i \in I_{1} \\
i \in I_{2} \\
i \in I_{3}
\end{array}\right\}
$$

$I_{1}$ 为效益型指标, $I_{2}$ 为成本型指标, $I_{3}$ 为适 度性指标, $a_{i}$ 为第 $\mathrm{i}$ 项指标的适度值。

$U_{i} *\left\{\begin{array}{c}\min \left\{a_{i j}\right\}(i \ll j \ll n) \\ \max \left\{a_{i j}\right\}\{i \ll j \ll n\} \\ a_{i} \pm \max \left|a_{i j}-a_{i}\right|(1 \ll j \ll n)\end{array}\right.$

(2)构造各方案与 $U_{i}^{*}, U_{i} *$ 的相对偏差矩阵

$$
\mathrm{R}=\left(r_{i j}\right)_{m \times n}, \Delta=\left(\delta_{i i j}\right)_{m \times n}
$$

$r_{i j}\left\{\begin{array}{l}1-\frac{\left|U_{i}^{*}-a_{i}\right|}{\left|a_{i j}-a_{i}\right|} \\ \frac{\left|U_{i}^{*}-a_{i j}\right|}{\max \left\{a_{i j}\right\}-\min \left\{a_{i j}\right\}} \\ j\end{array}\right.$

$\delta_{i j}=$

$\left\{\begin{array}{l}1-\frac{\left|U_{i}^{*}-a_{i}\right|}{\left|a_{i j}-a_{i}\right|} \\ \frac{\mid U_{i^{*}-a_{i j} \mid}}{\max \left\{a_{i j}\right\}-\min \left\{a_{i j}\right\}} \\ j\end{array}\right.$

$(i=1,2, \ldots, m ; j=1,2, \ldots n)$

(3)建立各评价指标的权重

首先计算 $\mathrm{R}$ 的行向量 $r_{i}$ 与 $\Delta$ 对应的行向量 $\delta$

的夹角余弦:

$C_{i}=\frac{\sum_{j=1}^{n} r_{i j} \delta_{i j}}{\sqrt{\sum_{j=1}^{n} r_{i j}^{2}} \sqrt{\sum_{j=1}^{n} \delta_{i j}^{2}}}(i=1,2, \ldots, m)$

然后将 $C_{i}$ 归一化得到 $\mathrm{m}$ 项评价指标的权向 量 $\bar{\omega}=\left(\omega_{1}, \omega_{2}, \ldots, \omega_{m}\right)$

其中 $\omega_{i}=\frac{C_{i}}{\sum_{i=1}^{m} C_{i}}(i=1,2, \ldots, m)$

最后得出综合评分 $s_{i}=\sum_{j=1}^{m} \omega_{i} p_{i j} \quad p_{i j}=$ $\frac{a_{i j}}{\sum_{i=1}^{n} a_{i j}}$

\section{4.实证研究}

\section{1 多目标客观赋权法合成系统性金}

\section{融风险综合指标}

运用多目标客观赋权法计算五个指标

\begin{tabular}{|c|c|c|c|c|c|c|}
\hline 指标. & $\mathrm{X}_{1, \mathrm{x}}$ & $x_{2, n}$ & $X_{3, n}$ & $X_{e_{n . x}}$ & $x_{5.3}$ & $x_{5.1}$ \\
\hline 权重 $\omega_{i}$, & 0.18269 & 0.22871 & 0.07331 & 0.13513. & 0.21054 & 0.16962 \\
\hline
\end{tabular}

的权重, 相关计算结果如表 3 所示,利用计算 所得权重得到风险综合评分如图 3 所示。

表 3 指标权重

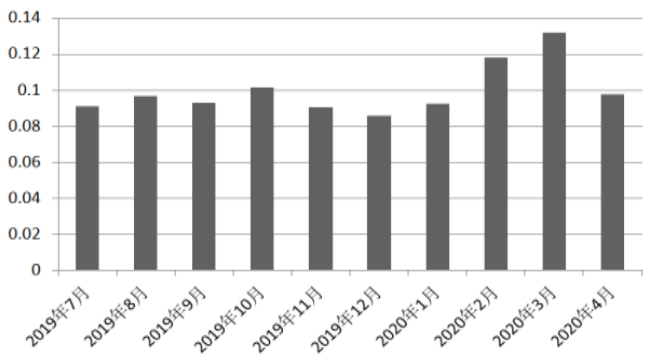

图 3 CSFR 得分走势图

\section{2 实证结果分析}

$i \in I_{3}$ 图 3 大致反映了我国 2019 年 7 月到 2020 年 4 月以股票市场为代表的金融系统 $i \notin I_{3}$ 风险的大致走势。从图 3 的趋势来说, 时间 速段分为三个区间进行分析更为恰当。

第一阶段（2019 年 7 月到 2019 年 11 月)结合图 3 和表 3 分析可知, 该阶段 CSFR 大致在 0.1 以下变动, 体现了我国股票市场 在没有新冠疫情冲击时风险指数在相对较 低的区间内波动且波动幅度较小。

第二阶段（2019 年 12 月到 2020 年 3 月), 该阶段 CSFR 指数开始飙升, 且大都 在 0.1 以上, 与前一阶段拉开明显差距。这 反映出新冠疫情对我国股票市场的影响程 度很深。[5]下面将主要从微观层面分析新冠 疫情对股票市场的影响, 以及我国政府, 企 业和投资者在风险波动中扮演的角色和起 到的作用。[6]

（1）投资者恐慌情绪蔓延，引发股票 抛售。疫情爆发时我国正处于春节期间, 股 市休市, 在此期间由于疫情加重, 武汉封城 等负面消息不断传来, 加上无良媒体的恶意 渲染，投资者对股票市场信心不足，对股票 市场存在很深的负面预期, 这种预期反映在 股票市场上就是 2020 年 2 月 3 日（春节后 的第一个交易日), 上证综指下跌 $7.72 \%$, 深证成指下跌 $8.45 \%$ 。

（2）实体资本反向引导股票市场下行。 在疫情取得有效防控成果后, 实体企业和金 融机构无法恢复到疫情前的运行状态, 导致 资产负债表盈利减少甚至亏损, 这种财务状 况对投资者的心理冲击直接导致股票下跌 和市场动荡。 
（3）疫情全球化放大股票市场外部风 险。在我国抗疫逐步取得成功, 资本市场自 行修复时, 国外抗击疫情失误、新冠病毒全 球蔓延。国外疫情结束了美国和欧洲国家长 达数十年之久的牛市, 证券市场连续 4 次熔 断。由于我国资本市场的逐步开放，外国资 本占 $\mathrm{A}$ 股总资本的比重不断攀升, 这意味着 外国资本的流入流出对我国金融市场的风 险贡献力提升。在国外疫情形势严峻时, 尽 管我国的疫情防控工作进展顺利, 企业顺利 复工复产, 股票市场的行情并没有与全球行 情完全独立, 而是面临连带下行风险。反映 在股票市场上, 呈现出股票市场回暖又遭连 带下跌的行情。

（4）政府主导的财政和货币政策实现 金融市场流通合理性。疫情期间我国采取 “积极的财政政策要更加积极有为, 稳健的 货币政策要更加灵活适度” 的宏观政策。[7] 在金融领域推进普惠金融建设和再贷款再 贴现等措施, 财政领域出台财政贴息、减税 降费、缓缴税款等措施, 在多个省会城市发 行消费券, 增发抗疫特别国债和地方政府专 项债券。这一系列的财政措施有利于保持金 融市场的流动性合理充裕。[8]

第三阶段（2020 年 4 月), 该月与前两 个月相比风险得分明显下降, 但依然高于前 七个月的绝大部分风险得分, 可见我国在疫 情防控上采取的措施已初见成效, 国家的财 政政策和货币政策对金融市场的流动性的 补充作用显现，市场投资者开始恢复信心。 这也反映出疫情对金融系统的风险影响在 短期内明显, 但就长期而言, 由于经济总体 形势并没有改变, 金融系统的风险也将趋于 稳定。但在此阶段仅仅只有 2020 年 4 月份 数据及得分, 对长期的影响分析还需要进一 步的数据分析。

\section{5. 风险应对策略启示与建议}

首先, 从国外国内对疫情的重视态度以 及金融市场动荡程度来看, 我国快速建立全 国性的联合防控机制, 采取封城、全民居家 的防疫措施, 短期内快速控制疫情更有利于 我国金融市场的稳定。所以应对金融外生冲 击风险的首要任务就是要化解冲击源。如果 冲击源作为市场动荡的导火索没有及时得 到有效控制，将会使投资者对市场失去信心， 这在很大程度上影响政府财政政策以及货 币政策能否有效实施。虽然我国在疫情暴发 初期采取严格的疫情防控措施, 相对于 2003 年非典疫情, 卫生应急体制的建设上升到新
的台阶, 但是仍然还有很大的建设及安全空 间。不仅仅是卫生应急体制, 社会安全应急 体制, 自然灾害应急体制都需要加强建设。 在事故突发时, 此类社会基础建设与应用对 预防金融系统外生冲击短期内起到决定作 用。[9]

其次, 面对此类重大冲击有必要采取非 常规政策, 对冲冲击。历史上传染病疫情证 明, 外生冲击短期内会造成巨大影响, 但长 期内随着资本市场自行修复, 金融风险趋于 稳定。所以在短期内对于非常态的金融市场 运行异常时可以采取非常规的政策措施, 在 短期内快速补充金融市场流动性, 创新财政 政策工具，并与货币政策协调并用，将更有 利于对冲短期金融风险，有效防止金融危机。

最后，关注国外财政及货币政策并做好 应对方案。次债危机中美国就通过宽松的货 币政策稀释债务, 和金融工具的创新套取发 展中国家资产从而实现了危机的转嫁。以中 国为代表的发展中国家为美国的危机买单, 国内产生输入性的通货膨胀和本币升值压 力大等问题。如今美国的疫情还在进一步扩 张并未出现向好势态, 并且股票市场已经发 生熔断。面对市场的流动性枯竭等危机时美 国的政策走向以及连带的世界各国的政策 走向都是未知的, 中国应该时刻警惕国外财 政政策, 及时调整政策以减少国际金融动荡 的连带效应。

\section{致谢}

本文受到项目资金资助: 2020 年度中央财经 大学大学生创新创业项目 “构建中国的纳斯 达克: 基于科创板评估体系的研究

（C2020103578）”、2020 年度国家民委民族 研究项目 “后脱贫时代西部藏区乡村振兴风 险与内置金融研究 (2020-GMB-030)”。

\section{参考文献}

[1]张博,刘雯. 基于股市异动的系统性风险分 析——兼论科创板的影响[J].投资研

究,2019,(10):147-158.

[2]洪健,雷汉云.系统性金融风险测度的指标 体系及评价[J].金融教育研

究,2020,33(3):34-41.

[3] 张博,刘雯. 基于股市异动的系统性风险分 析一一兼论科创板的影响[J].投资研

究,2019,(10):147-158.

[4]谭中明,夏琦.我国系统性金融风险与宏观 经济 波动关系: 指标度量与动态影响研究 [J]. 
金融理论与实践,2020,(3):8-16.

[5]刘婷, 郭明.新冠肺炎疫情对系统性金融风 险的影响机制研究[J].经济论

坛,2020,(6):67-72.

[6]李婧.新冠肺炎疫情对我国资本市场的影 响性分析及对策[J].北方金融,2020,(7):62-64. [7]杨宁嘉.新冠肺炎疫情下我国货币政策的 影响分析: 基于江西省新余市案例[J].金融与 经济,2020,(8):93-96.

[8]Zhou Hao, Sha Nan, Zhao Jing. China's systemic financial risk report in 2019:

preventing small and medium banks from disposing risks. TSINGHUA FINANCIAL

REVIEW,2020,(1):105-108.

[9]刘春华.新冠肺炎疫情与金融风险:影响与 对策[J].华北金融,2020,(3):1-7. 